\title{
The role of masculinities in psychological and emotional help-seeking by men with prostate cancer
}

\author{
Belinda C. Goodwin $^{\text {a,b }}$, Nicholas Ralph ${ }^{\text {a,b,d,e, }}$, Michael J. Ireland ${ }^{\text {b,c }}$, Melissa K. Hyde ${ }^{\text {i }}$, John \\ L. Oliffe ${ }^{\mathrm{f}}$, Jeff Dunn ${ }^{\mathrm{a}, \mathrm{b}, \mathrm{h}}$, and Suzanne Chambers ${ }^{\text {bee, }}$
}

Corresponding author:

Cancer Council Queensland

553 Gregory Terrace, Fortitude Valley, QLD, 4006

belindagoodwin@ cancerqld.org.au

${ }^{\mathrm{a}}$ Cancer Council Queensland, Brisbane, Australia

${ }^{\mathrm{b}}$ Centre for Health Research, University of Southern Queensland, Australia

${ }^{\mathrm{c}}$ School of Psychology, University of Southern Queensland, Australia

${ }^{\mathrm{d}}$ School of Nursing \& Midwifery, University of Southern Queensland, Australia

${ }^{\mathrm{e}}$ Faculty of Health, University of Technology Sydney, Australia

${ }^{\mathrm{f}}$ University of British Columbia, Vancouver, Canada

${ }^{\mathrm{g}}$ Edith Cowan University, Perth, Australia

${ }^{\mathrm{h}}$ Prostate Cancer Foundation of Australia, Sydney, NSW, Australia

${ }^{\mathrm{i}}$ School of Psychology, The University of Queensland, Brisbane, QLD, Australia

This is the author manuscript accepted for publication and has undergone full peer review but has not been through the copyediting, typesetting, pagination and proofreading process, which may lead to differences between this version and the Version of Record. Please cite this article as doi: $10.1002 /$ pon.5264

This article is protected by copyright. All rights reserved. 


\begin{abstract}
Objective: To assess the impact of demographic characteristics and masculinities on seeking support for psychosocial care needs in men with prostate cancer.

Method: Prostate cancer survivors $(\mathrm{n}=225)$ completed mail-out surveys measuring psychological care needs, masculinities, and psychological and emotional help-seeking intention and behaviour at six and 12-month follow ups.

Results: Older age was associated with seeking help from a GP, $\chi^{2}(1,225)=4.72, p=.03$, and being born overseas was associated with seeking peer support $(1,225)=7.13, p=.01$. Men with higher levels of optimistic action who reported moderate to high unmet psychological need were less likely to seek help for psychological and emotional concerns at $\operatorname{six}(\mathrm{OR}=0.06, \mathrm{CI}=0.01-0.46)$ and 12-month follow ups $(\mathrm{OR}=0.13, \mathrm{CI}=0.26-0.65)$. Conclusion: Optimistic action may explain why some men with prostate cancer fail to seek help for their psychological care needs. Clinicians should be aware that men with chronic illness who appear to approach challenges with optimistic action, may in fact be less likely to seek psychological help when needed.
\end{abstract}

Keywords: masculinities, prostatic neoplasms; psycho-oncology; psychosocial support systems;

This article is protected by copyright. All rights reserved. 


\section{Introduction}

Prostate cancer is a significant global health concern with approximately 1.4 million men diagnosed with the disease worldwide each year $(1,2)$. With advancements in prostate cancer treatment, the likelihood of living ten years after diagnosis has improved and survival rates are now at $90.6 \%$ in Australia (3), $98 \%$ in USA (4), and $84 \%$ in the United Kingdom (5). Nevertheless, increased survival does not necessarily translate to improved quality of life. Men can experience significant physical and psychological symptoms and declining healthrelated quality of life over time $(6,7)$. Ongoing physical and psychological burden is frequently reported by prostate cancer survivors with bowel, urinary and sexual dysfunction common in the five to fifteen years after treatment (6). In addition, men with prostate cancer report distress and uncertainty regarding their disease progression and prognosis leading to further psychological burden over time (8-14).

Almost 1 in 2 men diagnosed with prostate cancer report unmet psychological and psychosocial care needs (15) and although many studies report the prevalence of psychological need in prostate cancer patients $(13,15-17)$, few have identified the triggers or the frequency at which men seek support. In an Australian study $(n=76)$ of rural males living with cancer, younger men were found to be more likely to seek support from health professionals. The presence of anxiety, depression, and stress did not correspond with helpseeking behaviour (18). Actual levels of psychological and emotional distress may therefore be poor predictors of seeking support among men with cancer. Some studies associate psychosocial constructs such as self-reliance or stoicism with avoiding help-seeking for psychological needs (19-24), warranting investigation into other psychosocial predictors of help-seeking. 
Gendered dimensions of men's prostate cancer illness experiences such as masculinities may provide some insight into their help-seeking behaviours. Masculinities represent a framework of socially constructed gendered ideals to which men diversely align. Drawing on the work of Connell (1995), multiple masculinities reflect patterns and diversity in how men exhibit dominant ideals in terms of idealized characteristics, gendered hierarchies, and power relations (25). Connections between illness experiences and idealized characteristics of physical and emotional strength, competitiveness, stoicism, and self-reliance are often made in the literature on masculinities and prostate cancer (19). In the context of living with prostate cancer, men's alignment with these ideals have been reported to both amplify vulnerabilities and prohibit help-seeking $(19,26)$. However, masculine ideals have also been shown to facilitate the courage and strength to seek professional help and effective self-management skills as a means to maintaining (or regaining) independence $(7,19,20,27)$.

Perceived threats to masculinity in men with prostate cancer have been found to diminish their ability to process emotions during recovery and negatively impact their experiences, behaviours, and illness trajectory (28). By contrast, evidence suggests that strength-based masculinities can benefit cancer survivorship by men adopting problemsolving and rational thinking behaviours $(7,29)$. This is not to suggest a binary effect of masculine ideals (i.e., each as either being "good" or "bad" for men's health). Rather, masculinities may co-exist in men who are receiving biomedical prostate cancer care and diversely influence their experiences and behaviours at different life stages in the context of prostate cancer survivorship (30). For example, in some instances, masculine ideals that reflect strength and self-reliance may prevent the acknowledgement of distress or discomfort and inhibit communications with health professionals (30). In other instances, alignment to these ideals can result in men exhibiting rational thinking and problem-solving behaviours that lead to increased dialogue with health professionals (31). Taken together, this evidence 
supports and informs the development of measurement tools to itemize, capture, and account for gender norms in men who are living with chronic disease $(32,33)$. Drawing from gender socialization theory, masculine norms are typically listed in these measurement tools and men's alignments to these gendered dimensions are measured as a means to describe styles of coping, including problem-solving and self-management (28,34-36).

Given a high proportion of men with prostate cancer report unmet psychological care needs $(15,38)$ and ongoing poor quality of life, there is a need to understand how masculine ideals and norms influence men's help seeking for psychological and emotional concerns in the years following a prostate cancer diagnosis. To date, evidence regarding masculinities and men's health-related help seeking behaviours have relied on cross-sectional survey studies or qualitative research, limiting the capacity to draw conclusions regarding causality and the generalizability of findings. Accordingly, we sought to prospectively assess the predictors of psychological and emotional help-seeking behaviour in men with high levels of unmet psychological support needs after a diagnosis of prostate cancer.

The study uses longitudinal methodology to identify demographic associations with psychological and emotional help-seeking and explore the temporal associations between masculinities and help-seeking. Given that reported high needs for psychological and emotional support may not translate to higher levels of help-seeking (18), there is likely to be more variance in help-seeking behaviours in this group compared to those with less need for support (i.e., those with high needs may or may not seek help, but for the most part those without need, would not seek help). For this reason, we predict that the effect of masculinities on help-seeking will only be evident in those who report a moderate to high degree of need for psychological support. Findings provide a valuable contribution to designing targeted interventions aimed at improving the well-being of men with chronic illness who have the highest level of need for psychological care 


\section{Method}

\section{Participants and procedure}

Respondents ( $\mathrm{n}=225)$ were men who had been diagnosed with localized prostate cancer and had participated in an earlier component of the study (21). Recruited through the Queensland Cancer Registry (QCR), respondents: (1) had undergone or were currently undergoing prostate cancer treatment; (2) were able to read and speak English; (3) had no previous history of head injury, dementia, or psychiatric illness; (4) had no concurrent cancer; and (5) were given physician clearance. Questionnaires were sent to 400 eligible participants who had completed a questionnaire as part of an earlier component of the study. A total of 225 returned the questionnaire thereby consenting to participate in this extension phase. The men who consented did not differ significantly in age or education compared with those who did not consent $(n=175)$. Questionnaires were posted to participants and returned via mail at each timepoint. The number of participants returning follow-up questionnaires was 212 at 6 months (94\% response rate), and 206 at 12-month follow-up (92\% response rate).

The age of participants ranged from 47 to 87 years $(M=67.74, S D=7.20)$ and the majority of participants were married or in a relationship (89\%) and born in Australia (74\%) with $12 \%$ born in the UK, and $5 \%$ in European countries. The large majority of the sample (over $90 \%$ at each time point) were not currently, or had not in the last six months, undergone treatment for their prostate cancer. This reflects the fact that, on average, participants were 4.1 $(\mathrm{SD}=0.31)$ years post diagnosis for this extension study. Ethical approval for the study was granted from the Griffith University Human Research Ethics Committee (PSY/F6/10/HREC).

\section{Measures}

Demographic and treatment details. Participant age, marital status, education level, and country of birth were recorded at baseline, and treatment details including whether the 
respondent had undergone treatment in the past 6 months or was currently undergoing treatment were recorded at all time points.

Masculinities. The five-factor version of the Masculinity in Chronic Disease Inventory (MCD-I) was designed to measure the masculine beliefs and ideologies of men with prostate cancer $(32,33)$. The instrument measures five domains of masculinity including physical strength and fitness (3-items, e.g. "Being an active person is important to me"), sexual importance (4-items, e.g. "I like to know I am capable of having sex"), family responsibility (4-items, e.g. "It is up to me to protect my partner/family"), emotional selfreliance (2-items, e.g. "I keep my feelings to myself”), and optimistic action (9-items, e.g. "I like to take action in the face of problems"). Items are scored on a 1-5 point Likert scale (1 = "Not at all true", 5 = "Very true"). Items in each of the domains were measured at baseline and mean scores reflected the five continuous masculinity variables. Item Cronbach's alphas ranged from $\alpha=.72$ to .93 , demonstrating good to excellent internal reliability

Unmet psychological needs. The degree of unmet need for psychological support was measured at baseline using the psychological subscale of the Supportive Care Needs Survey Short Form-34 (SCNS-SF34; 22). Items such as "In the last month I have needed help with uncertainty about the future" and "In the last month I have needed help with feeling down and depressed" were rated as 1 ("no need/not applicable"), 2 ("need was satisfied"), 3 ("some need"), 4 (“moderate need"), or 5 ("high need"). The Cronbach's alphas for the subscale across the three time-points in the study were $\alpha=.92, \alpha=.94$, and $\alpha=.93$ demonstrating excellent internal reliability. A binary "moderate to high need" variable was created whereby men who reported a moderate to high need on at least one item were coded as ' 1 ' for "yes" and those who did not, were coded as ' 0 ' for "no".

Psychological and emotional help-seeking. Help-seeking for psychological and emotional concerns was measured at all three time points. By responding either "yes"/"no", 
participants indicated whether they were currently seeking, or had recently (in last six months), sought help for psychological or emotional concerns from a GP, a nurse, a psychologist or counsellor, a prostate cancer support group, another man with prostate cancer (peer support), or from another source. From this, three variables were created that reflected whether participants reported seeking any (i.e., one or more) forms of support for psychological and emotional concerns by six months post baseline, 12 months post baseline, or at any point across the 18-month duration of the study (i.e., including at baseline). In addition to this, participants were asked at baseline whether they intended to seek help within the next six months from any of the sources listed above. Those who selected "yes" to one or more source were coded as ' 1 ,' and those who did not were coded as ' 0 '.

\section{Analysis}

Percentages of participants seeking help for psychological needs during the entire study timeframe (at baseline, six months, or 12 months) were calculated for each method of help-seeking and overall. A set of 2x2 Pearson's chi-square analyses were used to assess whether membership in binary age, education, place of birth, and marital status groups were associated with a higher likelihood of help-seeking for psychological needs during the study timeframe. Using logistic regression analyses, age adjusted odds ratios (OR) and 95\% confidence intervals (CI) were calculated to assess the effect of each masculinity and psychological needs at baseline on help-seeking at six and 12 months and on intent to seek help at baseline. A masculinity by psychological need interaction variable was included in each model. The alpha level for determining statistical significance was set at .05. According to a-priori tests of power $(1-\beta$ err prob $=0.95)$, a minimum sample size of 20 was required to detect a small effect ( $w=.30)$ using chi square tests and a minimum sample size of 225 was required to detect a small to medium effect $(\mathrm{OR}=0.50)$ using logistic regression analyses.

\section{Results}




\section{Psychological and emotional help-seeking, sources of support, and demographic predictors}

Thirty-three percent of participants reported some degree of unmet psychological needs at baseline $(n=75)$. Of those who reported some degree of unmet psychological needs, $41 \%(\mathrm{n}=31)$ intended to seek psychological or emotional support within six months of baseline. Twenty seven percent $(n=20)$ of those who reported some degree of unmet psychological needs did seek support within six months of baseline and $33 \%(n=25)$ did so within 12 months of baseline.

Table 1 details the proportion of participants who sought psychological or emotional support from various sources throughout the 18-month study period according to their membership within various demographic groups. The most common source from which help was sought was a GP. Over $25 \%$ of the sample sought help from their GP and almost $20 \%$ sought support from peers. Seeking help for psychological and emotional concerns through a nurse (13\%), psychologist (13\%), or prostate cancer support group (12\%) was less common.

\section{Insert Table 1.}

Very few statistically significant demographic differences in support-seeking were apparent. Men under 65-year-old were more likely to seek psychological help from a GP, $\chi^{2}$ $(1,225)=4.72, p=.03$, compared to those over 65 . Men who were born overseas were more

likely to seek support from a nurse, $\chi^{2}(1,225)=4.24, p=.04$, or from a support group, $\chi^{2}$ $(1,225)=7.13, p=.01$, compared to Australian-born participants.

\section{Masculinities, unmet needs, and psychological and emotional help-seeking}

Table 2 shows the bivariate correlations between each of the study variables. Age was significantly related to psychological and emotional help-seeking at six months $(r=-.15, p=$ $.03)$ and 12 months $(r=-.16, p=.02)$, with younger participants more likely to seek support. No masculinities were associated with psychological and emotional help-seeking at either 
time point; however, increased sexual importance $(r=.13, p=.05)$ and family responsibility $(r=.14, p=.04)$ were weakly and positively associated with increased intention to seek support at baseline. A moderate to high degree of psychological needs was weakly and marginally associated with psychological and emotional help-seeking at each time point ( $\left.\left.r_{6 \text { months }}=.13, p=.06\right) ; r_{12 \text { months }}=.11, p=.09\right)$; however, there was a small to medium positive association between psychological care needs and intent to seek support at baseline. $(r=.37$, $p<.01$. Intention to seek support at baseline was also positively associated with actual helpseeking at six months $(r=.39, p<.01$ and 12 months $(r=.33, p<.01)$.

\section{Insert Table 2.}

Tables 3 details the masculinities by psychological need interaction effects on psychological and emotional support-seeking at six months and by 12 months. For the most part, sub-domains of masculinity had little to no effect on support seeking regardless of levels of unmet psychological needs. However, there was a significant interaction between optimistic action and psychological needs at both six months (Wald $=7.25, p<.01$ ) and 12 months $($ Wald $=6.17, p=.01)$. As shown in Figure 1, men who reported higher levels of optimistic action were less likely to seek support at six months $(\mathrm{OR}=0.06, \mathrm{CI}=0.01-0.46)$ or at 12 months $(\mathrm{OR}=0.13, \mathrm{CI}=0.26-0.65)$ if their psychological needs were high.

\section{Insert Table 3}

\section{Insert Figure 1}

Table 3 details the masculinity sub-domain by psychological needs interaction effects on intent to seek help at baseline. Masculinities had little effect on intentions to seek support; however, there were marginally significant interactions between optimistic action and psychological needs $($ Wald $=4.00, p=.05)$ and sexual importance and psychological needs (Wald $=1.35, p=.05$ ) on intention to seek help at baseline. Men who reported a moderate to high level of unmet psychological care needs at baseline had a weak tendency to report 
intending to seek support if they were also high in sexual importance $(\mathrm{OR}=0.48, \mathrm{CI}=0.23$ $1.400)$ and optimistic action $(\mathrm{OR}=0.95, \mathrm{CI}=0.01-1.01)$. Supplementary Figure 1 , depicting the interaction is supplied as supplementary material.

\section{Discussion}

The current study investigated psychological and emotional help-seeking behaviour in men with prostate cancer several years post-treatment and found that only a minority of respondents who reported a need for such support, actively sought it. Those who did seek support tended to be younger and sourced it largely from their GP or through prostate cancer support groups. Those with the highest degree of need for psychological support were less likely to seek this support if they were high in optimistic action; an alignment to masculine norms that reflects an orientation toward taking positive action in the face of challenges (32).

Our findings highlight how this masculine characteristic can help explain why many men with prostate cancer so often report unmet psychological and emotional needs $(14,16,39)$. The importance of psychological and emotional well-being is increasingly being emphasised as part of survivorship care (7); yet at least $70 \%$ of respondents in the current study who required support, failed to seek it within 12 months since baseline. This means a large proportion of prostate cancer survivors who are experiencing treatment do not seek help for emotional and psychological issues, and therefore, their needs remain unmet over time.

The current study demonstrated that intention to seek support was only moderately associated with subsequently accessing care. A more complex finding, however, is that some men who intend to seek psychological support, do so, while other men who are high in optimistic action (I like to take action in the face of problems) tend not to seek help. Although similarities appear between taking action and help-seeking intention, subtle differences in the two concepts may be explained by masculine models of coping. For instance, communicating 
an intention to seek help may represent both an admission of psychological or emotional needs (potentially transgressing masculine ideals by admitting vulnerabilities) and a specific plan to address these needs (aligning to masculine ideals for decisiveness and problemsolving). This disclosure of vulnerability might be countered by a constructive problemsolving approach (reflecting some normative masculine characteristics) previously reported in men with prostate cancer (40). When men communicate a need and an intention to take action, but fail to formulate a plan or to take action in an adaptive manner (e.g., seeking support) this confirms the limits of self-disclosure and vulnerabilities for many men (e.g., avoidance, negative problem orientation) (40). Men who express optimistic action may therefore be coping by stating they will take action, when in fact, the action subsequently taken is to engage in negative coping strategies such as avoidant thinking, redirecting cognition and attention, retaining pre-illness identity, or variations across each (41).

Masculinities have long been touted as action orientations, wherein aligning with gendered norms has prevailed as a major lever for both denying illness and promoting one's health within the context of living with prostate cancer. Herein, the current study findings reveal significant complexities and some contradictions in men's help-seeking for prostate cancer. For example, while barriers to accessing prostate cancer care have included a lack of familiarity with health systems and the absence of gender-sensitized services, men's alignments to some masculine norms appear to prevent their promised help-seeking. Optimism, in this context, emerges as the capacity to carry on independently, and without complaint - thus preserving important masculine norms central to 'fighting the disease' synonymous with prostate cancer.

There are contexts and caveats to these findings. Foremost, that younger men were more likely to seek help might reflect shifting masculine values (42) wherein the necessity for better well-being overrides any hesitation to seek professional or peer support. That foreign- 
born men were more likely to access peers for support, affirms the plurality of masculinities; moreover, this diversity might be explained by connections between gender and culture that affirm some men's deep social connectedness - and by extension their self-disclosures and reciprocity for mutual help. Though a preliminary finding, this result highlights the importance of tailoring culturally-sensitive interventions and services, reflecting our recognition that gender intersects with an array of social determinants of health including culture, place, income, and education. In essence, it may be that community peer-based psychological care is most acceptable to and engaging of immigrant men who are living with prostate cancer. The other age-related finding that men under 65 years of age were more likely to access GPs for psychological care might also be explained by older men (i.e., > 65 years old) being in specialist care that was not necessarily inclusive of, or focussed on, psychological help. These findings offer an important reminder of agency and structure wherein men's help-seeking interacts with health care systems that triage specific care.

\section{Study Limitations}

Some caution must be applied in generalising the current findings to samples of men with other chronic diseases given prostate cancer survivors are diverse and can differ on key variables including age. Furthermore, the sample was restricted in that all men were between three and six-years post-treatment. Self-report measures of intentions, particularly in health behaviour research, are inherently subject to some degree of bias due to social desirability (43). Furthermore, potential for response bias exists in that the profile of men who agree to take part in research may differ to those who do not. It is important to consider this when interpreting relationships between intentions to seek help and actual help-seeking behaviour in the current study.

Given men with prostate cancer are known to attempt active avoidance of confronting the psychological consequences of the disease (41), further research is needed to develop 
gender-sensitized approaches that support men to self-assess their psychological needs and develop action plans to fully address them. Since optimistic action effects men's help-seeking for psychological and emotional concerns, this masculine ideal should be investigated in terms of its relationship to other behavioural outcomes such as treatment adherence, adherence to health advice, and participation in intervention trials.

\section{Clinical Implications}

With high unmet psychological and emotional needs persisting in men with prostate cancer over the last two decades $(13,15)$, different mechanisms may need to be introduced to target psychological help-seeking in those men who espouse intent but tend to avoid it. Clinicians should be aware that men with chronic illness who appear to approach challenges with optimistic action, may in fact be in need of psychological care but less likely to seek help and must therefore continue to prompt, facilitate, and follow-up with them regarding their efforts to seek appropriate support. To promote psychological help-seeking in this at-risk subgroup, actively engaging help might be reframed and affirmed as strength-based positive actions to solving significant problems. Moreover, the benefits of improved well-being for men might be formally linked to aiding family and friends to appeal to men's ideals about protecting others.

\section{Conclusions}

The current study is the first to address the predictors of psychological and emotional help-seeking using longitudinal measures in a large, representative sample of prostate cancer survivors in the years following treatment. Findings demonstrate that masculinities are largely unrelated to help-seeking for psychological and emotional concerns, with the exception of optimistic action. A heightened orientation toward taking positive action in the face of chronic disease may help to explain why some men with prostate cancer fail to seek help for their psychological care needs. Men with chronic illness who appear to approach prostate cancer 
challenges with optimistic action, may in fact be less likely to seek psychological help when needed.

\section{Acknowledgements}

We would like to thank the research participants for taking part in the study. We also acknowledged the efforts of research team members Anna Stiller (Pamo Lenzang) and Lisa Nielsen in assisting with project management, participant recruitment and data collection.

\section{Conflict of interest}

The authors of this manuscript have no conflicts of interest to disclose.

\section{Data availability statement}

The data that support the findings of this study are available from the corresponding author upon reasonable request. 


\section{References}

1. Bray F, Lortet-Tieulent J, Ferlay J, Forman D, Auvinen A. Prostate cancer incidence and mortality trends in 37 European countries: an overview. European journal of cancer. 2010;46(17):3040-3052.

2. Wong MC, Goggins WB, Wang HH, Fung FD, Leung C, Wong SY, et al. Global incidence and mortality for prostate cancer: analysis of temporal patterns and trends in 36 countries. European urology. 2016;70(5):862-874.

3. AIHW. Australian Cancer Database, 2014. Australian Government: Canberra;

4. American Cancer Society. Survival Rates for Prostate Cancer. [Internet]. [cited 2019 Feb 7]. Available from: Available from: https://www.cancer.org/cancer/prostatecancer/detection-diagnosis-staging/survival-rates.html.

5. Cancer Research UK. Prostate cancer survival statistics. [Internet]. 2019 [cited 2019 Feb 25]. Available from: [accessed 2019 February 25]; Available from:

https://www.cancerresearchuk.org/health-professional/cancer-statistics/statistics-bycancer-type/prostate-cancer/survival\#heading-Two.

6. Resnick MJ, Koyama T, Fan K-H, Albertsen PC, Goodman M, Hamilton AS, et al. Longterm functional outcomes after treatment for localized prostate cancer. New England Journal of Medicine. 2013;368(5):436-445.

7. Courtenay WH. Engendering health: A social constructionist examination of men's health beliefs and behaviors. Psychology of Men \& Masculinity. 2000;1(1):4.

8. Smith DS, Carvalhal GF, Schneider K, Krygiel J, Yan Y, Catalona WJ. Quality-of-life outcomes for men with prostate carcinoma detected by screening. Cancer. 2000;88(6):1454-63.

9. Litwin MS, Lubeck DP, Spitalny GM, Henning JM, Carroll PR. Mental health in men treated for early stage prostate carcinoma. Cancer. 2002;95(1):54-60.

10. Pickles T, Ruether JD, Weir L, Carlson L, Jakulj F. Psychosocial barriers to active surveillance for the management of early prostate cancer and a strategy for increased acceptance. BJU international. 2007;100(3):544-51.

11. Goodwin BC, March S, Zajdlewicz L, Osborne RH, Dunn J, Chambers SK. Health literacy and the health status of men with prostate cancer. Psycho-Oncology. 2018;27(10):2374-2381.

12. Ettridge KA, Bowden JA, Chambers SK, Smith DP, Murphy M, Evans SM, et al. "Prostate cancer is far more hidden...": Perceptions of stigma, social isolation and helpseeking among men with prostate cancer. Eur J Cancer Care (Engl). 2018 Mar;27(2):e12790. 
13. Stinesen Kollberg K, Thorsteinsdottir T, Wilderäng U, Hugosson J, Wiklund P, Bjartell A, et al. Social constraints and psychological well-being after prostate cancer: A followup at 12 and 24 months after surgery. Psychooncology. 2018 Feb;27(2):668-75.

14. Lintz K, Moynihan C, Steginga S, Norman A, Eeles R, Huddart R, et al. Prostate cancer patients' support and psychological care needs: survey from a non-surgical oncology clinic. Psycho-Oncology. 2003;12(8):769-83.

15. Hyde MK, Newton RU, Galvao DA, Gardiner RA, Occhipinti S, Lowe A, et al. Men's help-seeking in the first year after diagnosis of localised prostate cancer. European journal of cancer care. 2017;26(2):e12497.

16. Watson E, Shinkins B, Frith E, Neal D, Hamdy F, Walter F, et al. Symptoms, unmet needs, psychological well-being and health status in survivors of prostate cancer: implications for redesigning follow-up. BJU international. 2016;117(6B):E10-E19.

17. Balderson N, Towell T. The prevalence and predictors of psychological distress in men with prostate cancer who are seeking support. Br J Health Psychol. 2003 May;8(Pt 2):125-34.

18. Corboy D, McLaren S, McDonald J. Predictors of support service use by rural and regional men with cancer. Australian Journal of Rural Health. 2011;19(4):185-190.

19. Addis ME, Mahalik JR. Men, masculinity, and the contexts of help seeking. American psychologist. 2003;58(1):5.

20. MacKenzie CS, Gekoski WL, Knox VJ. Age, gender, and the underutilization of mental health services: The influence of help-seeking attitudes. Aging \& Mental Health. 2006 Nov 1;10(6):574-82.

21. Chapple A, Ziebland S. Prostate cancer: embodied experience and perceptions of masculinity. Sociology of Health \& Illness. 2002;24(6):820-841.

22. George A, Fleming P. Factors affecting men's help-seeking in the early detection of prostate cancer: implications for health promotion. Journal of men's health and gender. 2004;1(4):345-352.

23. Reevy GM, Maslach C. Use of social support: Gender and personality differences. Sex roles. 2001;44(7-8):437-459.

24. Murray G, Judd F, Jackson H, Fraser C, Komiti A, Pattison P, et al. Big boys don't cry: An investigation of stoicism and its mental health outcomes. Personality and Individual Differences. 2008;44(6):1369-81.

25. Connell RW. Masculinities. Berkeley. University of California press CA; 1995.

26. Donaldson M. What is hegemonic masculinity? Theory and society. 1993;22(5):643-657.

27. Leone JE, Rovito MJ, Mullin EM, Mohammed SD, Lee CS. Development and Testing of a Conceptual Model Regarding Men's Access to Health Care. Am J Mens Health. 2017;11(2):262-74. 
28. Hoyt MA, Stanton AL, Irwin MR, Thomas KS. Cancer-related masculine threat, emotional approach coping, and physical functioning following treatment for prostate cancer. Health Psychology. 2013;32(1):66.

29. Sloan C, Gough B, Conner M. Healthy masculinities? How ostensibly healthy men talk about lifestyle, health and gender. Psychology and Health. 2010;25(7):783-803.

30. Oliffe J. Health behaviors, prostate cancer, and masculinities: a life course perspective. Men and Masculinities. 2009;11(3):346-366.

31. Oliffe J, Thorne S. Men, masculinities, and prostate cancer: Australian and Canadian patient perspectives of communication with male physicians. Qualitative Health Research. 2007;17(2):149-161.

32. Occhipinti S, Laurie K, Hyde MK, Martin S, Oliffe J, Wittert G, et al. Measuring Masculinity in Men with Chronic Disease. American Journal of Men's Health. 2019;13(4).

33. Chambers SK, Hyde MK, Oliffe JL, Zajdlewicz L, Lowe A, Wootten AC, et al. Measuring masculinity in the context of chronic disease. Psychology of Men \& Masculinity. 2016;17(3):228.

34. Ralph, N., S. Chambers, A. Pomery, J. Oliffe and J. Dunn,. Ralph, N., S. Chambers, A. Pomery, J. Oliffe and J. Dunn, Nurse-Led Supportive Care Intervention for Men With Advanced Prostate Cancer. Oncol Nurs Forum,. 2019;46(1):92-103.

35. Burns SM, Mahalik JR. Understanding How Masculine Gender Scripts May Contribute to Men's Adjustment Following Treatment for Prostate Cancer. Am J Mens Health. 2007 Dec 1;1(4):250-61.

36. Sexual Functioning as a Moderator of the Relationship Between Masculinity and Men's Adjustment Following Treatment for Prostate Cancer - Shaun Michael Burns, James R. Mahalik, 2008 [Internet]. [cited 2019 Sep 17]. Available from: https://journals.sagepub.com/doi/abs/10.1177/1557988307304325

37. Thompson Jr EH, Bennett KM. Measurement of masculinity ideologies: A (critical) review. Psychology of Men \& Masculinity. 2015;16(2):115.

38. Chambers SK, Hyde MK, Smith DP, Hughes S, Yuill S, Egger S, et al. New Challenges in Psycho-Oncology Research III: A systematic review of psychological interventions for prostate cancer survivors and their partners: clinical and research implications. PsychoOncology. 2017 Jul 1;26(7):873-913.

39. Steginga SK, Campbell A, Ferguson M, Beeden A, Walls M, Cairns W, et al. Sociodemographic, psychosocial and attitudinal predictors of help seeking after cancer diagnosis. Psycho-oncology. 2008 Oct;17(10):997-1005.

40. Ko CM, Malcarne VL, Varni JW, Roesch SC, Banthia R, Greenbergs HL, et al. Problemsolving and distress in prostate cancer patients and their spousal caregivers. Supportive Care in Cancer. 2005;13(6):367-374. 
41. Spendelow JS, Joubert HE, Lee H, Fairhurst BR. Coping and adjustment in men with prostate cancer: a systematic review of qualitative studies. Journal of Cancer Survivorship. 2018;12(2):155-168.

42. Oliffe JL, Rice S, Kelly MT, Ogrodniczuk JS, Broom A, Robertson S, et al. A mixedmethods study of the health-related masculine values among young Canadian men. Psychology of Men \& Masculinity. 2018;

43. DeMaio TJ. Social desirability and survey. Surveying subjective phenomena. 1984;2:257. 
Table 1. Proportion of participants from each demographic group seeking help from each source over the study period.

\begin{tabular}{|c|c|c|c|c|c|c|}
\hline & $\begin{array}{c}\text { GP } \\
\mathrm{n}(\%)\end{array}$ & $\begin{array}{l}\text { Nurse } \\
\mathrm{n}(\%)\end{array}$ & $\begin{array}{c}\text { Psychologist } \\
\mathrm{n}(\%)\end{array}$ & $\begin{array}{l}\text { Support } \\
\text { group } \\
\mathrm{n}(\%) \\
\end{array}$ & $\begin{array}{c}\text { Peer } \\
\text { support } \\
\text { n }(\%)\end{array}$ & $\begin{array}{c}\text { Any } \\
\mathrm{n}(\%)\end{array}$ \\
\hline \multicolumn{7}{|l|}{ Age (T1) } \\
\hline 65 and under & $28(34.1 \%)$ & $11(13.4 \%)$ & $14(17.1 \%)$ & $10(12.2 \%)$ & $19(23.2 \%)$ & $30(36.6 \%)$ \\
\hline Over 65 & $30(21.0 \%)$ & $18(12.6 \%)$ & $16(11.2 \%)$ & $18(12.6 \%)$ & $23(16.1 \%)$ & $36(25.2 \%)$ \\
\hline \multicolumn{7}{|l|}{ Tertiary education } \\
\hline no & $18(23.7 \%)$ & $9(11.8 \%)$ & $10(13.2 \%)$ & $9(11.8 \%)$ & $14(18.4 \%)$ & $23(30.3 \%)$ \\
\hline yes & $40(26.8 \%)$ & $20(13.4 \%)$ & $20(13.4 \%)$ & $19(12.8 \%)$ & $28(18.8 \%)$ & $43(28.9 \%)$ \\
\hline \multicolumn{7}{|l|}{ Born in Australia } \\
\hline no & $17(29.3 \%)$ & $12(20.7 \%)$ & $9(15.5 \%)$ & $13(22.4 \%)$ & $14(24.1 \%)$ & $20(34.5 \%)$ \\
\hline yes & $41(24.6 \%)$ & $17(10.2 \%)$ & $21(12.6 \%)$ & $15(9.0 \%)$ & $28(16.8 \%)$ & $46(27.5 \%)$ \\
\hline \multicolumn{7}{|l|}{ Marital status (T1) } \\
\hline married & $50(24.9 \%)$ & $25(12.4 \%)$ & $27(13.4 \%)$ & $23(11.4 \%)$ & $38(18.9 \%)$ & $55(27.4 \%)$ \\
\hline not married & $8(33.3 \%)$ & $4(16.7 \%)$ & $3(12.5 \%)$ & $5(20.8 \%)$ & $4(16.75)$ & $11(45.8 \%)$ \\
\hline Total & $58(25.8 \%)$ & $29(12.9 \%)$ & $30(13.3 \%)$ & $28(12.4 \%)$ & $42(18.7 \%)$ & $66(29.3 \%)$ \\
\hline
\end{tabular}

This article is protected by copyright. All rights reserved. 
Table 2. Zero order correlations between demographics masculinities, unmet psychological needs, and help-seeking.

\begin{tabular}{|c|c|c|c|c|c|c|c|c|c|c|c|}
\hline & 1 & 2 & 3 & 4 & 5 & 6 & 7 & 8 & 9 & 10 & 11 \\
\hline 1. In a relationship & 1.00 & & & & & & & & & & \\
\hline 2. Age & -.06 & 1.00 & & & & & & & & & \\
\hline 3.Years since diagnosis & -.01 & .05 & 1.00 & & & & & & & & \\
\hline 4. MCDI: Optimistic Action & .06 & -.07 & -.06 & 1.00 & & & & & & & \\
\hline 5. MCDI: Sexual importance/priority & .12 & $-.34^{* *}$ & -.05 & .09 & 1.00 & & & & & & \\
\hline 6. MCDI: Family responsibilities & $.45^{* *}$ & .05 & -.01 & $.40^{* *}$ & $.18^{* *}$ & 1.00 & & & & & \\
\hline 7. MCDI: Emotional Self-Reliance & -.06 & .05 & .04 & $.14^{*}$ & $.17^{*}$ & 0.11 & 1.00 & & & & \\
\hline 8. MCDI: Strength \& phys. fitness & .07 & -.01 & -.04 & $.57^{* *}$ & $.14^{*}$ & $.33^{* *}$ & $.22^{* *}$ & 1.00 & & & \\
\hline 9. Mod/high Psych need (baseline) & .08 & -.09 & -.07 & .02 & $.27^{* *}$ & $.15^{*}$ & $.15^{*}$ & .05 & 1.00 & & \\
\hline 10. Psych help-seeking at 6 months & -.05 & $-.15^{*}$ & -.05 & -.07 & .10 & -.04 & .06 & -.07 & .13 & 1.00 & \\
\hline 11. Psych help-seeking by 12 months & -.08 & $-.16^{*}$ & -.04 & .00 & .08 & .01 & .12 & -.02 & .11 & $.79^{* *}$ & 1.00 \\
\hline 12. Intent to seek support at baseline & .05 & -.12 & .01 & -.05 & $.13^{*}$ & $.14^{*}$ & .09 & -.03 & $.37^{* *}$ & $.39^{* *}$ & $.33^{* *}$ \\
\hline
\end{tabular}

This article is protected by copyright. All rights reserved. 
Table 3. Moderating effects of baseline masculinities and unmet psychological needs on psychological and emotional help-seeking at 6 and 12 month follow up and intention at baseline

\begin{tabular}{|c|c|c|c|c|c|}
\hline Unmet psychological need $x$ & Wald & $p$ & $\mathbf{O R}_{\mathbf{a}}$ & LCI & UCI \\
\hline \multicolumn{6}{|l|}{ Outcome: Help-seeking - 6 months } \\
\hline Optimistic Action & 7.25 & .007 & 0.06 & 0.01 & 0.46 \\
\hline Sexual Importance & .287 & .115 & 0.57 & 0.29 & 1.15 \\
\hline Family Responsibility & 2.01 & .156 & 0.28 & 0.06 & 1.59 \\
\hline Emotional Self-reliance & 2.35 & .125 & 0.48 & 0.19 & 1.23 \\
\hline Strength and physical fitness & 0.99 & .136 & 0.38 & 0.11 & 1.36 \\
\hline \multicolumn{6}{|l|}{ Outcome: Help-seeking - 12 months } \\
\hline Optimistic Action & 6.17 & .013 & 0.13 & 0.26 & 0.65 \\
\hline Sexual Importance & 3.26 & .072 & 0.55 & 0.29 & 1.05 \\
\hline Family Responsibility & 1.08 & .298 & 0.44 & 0.10 & 2.05 \\
\hline Emotional Self-reliance & 2.33 & .127 & 0.52 & 0.22 & 1.21 \\
\hline Strength and physical fitness & 2.84 & .092 & 0.36 & 1.11 & 1.18 \\
\hline \multicolumn{6}{|l|}{ Outcome: Intent to seek help - baseline } \\
\hline Optimistic Action & 4.00 & .046 & 0.95 & 0.90 & 1.01 \\
\hline Sexual Importance & 1.35 & .050 & 0.48 & 0.23 & 1.00 \\
\hline Family Responsibility & 0.87 & .350 & 2.44 & 0.38 & 15.92 \\
\hline Emotional Self-reliance & 0.08 & .769 & 1.15 & 0.46 & 2.90 \\
\hline Strength and psychical fitness & 0.72 & .395 & 0.58 & 0.17 & 2.02 \\
\hline
\end{tabular}

${ }^{\mathrm{a}}$ ORs adjusted for age. Bolded $=$ significant at $\mathrm{p}<.05$,

Figure 1. Simple slopes analysis of the relationship between optimistic action and for psychological and emotional help-seeking (at 6 months) in men with no-low versus those with mod- high needs.

Supplementary Figure 1. Simple slopes analysis of the relationship between optimistic action and for psychological and emotional help-seeking (by 12 months) in men with nolow versus those with mod- high needs. 


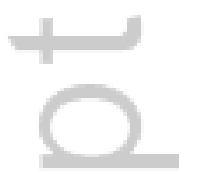

4 


\section{University Library}

\section{- M M N E R VA A gateway to Melbourne's research publications}

Minerva Access is the Institutional Repository of The University of Melbourne

Author/s:

Goodwin, BC;Ralph, N;Ireland, MJ;Hyde, MK;Oliffe, JL;Dunn, J;Chambers, S

Title:

The role of masculinities in psychological and emotional help seeking by men with prostate cancer.

Date:

2020-02

Citation:

Goodwin, B. C., Ralph, N., Ireland, M. J., Hyde, M. K., Oliffe, J. L., Dunn, J. \& Chambers, S. (2020). The role of masculinities in psychological and emotional help seeking by men with prostate cancer.. Psychooncology, 29 (2), pp.356-363. https://doi.org/10.1002/pon.5264.

Persistent Link:

http://hdl.handle.net/11343/286637 